\title{
Over The Air Update Firmware pada Perangkat IoT Dengan Protokol MQTT
}

\author{
Luqman Hakim, Wahyu Andhyka Kusuma², Mahar Faiqurahman ${ }^{3}$, Supriyanto $^{4}$ \\ Universitas Muhammadiyah Malang \\ e-mail: ${ }^{1}$ luqman.hakim@umm.ac.id, ${ }^{2}$ wahyukusuma@umm.ac.id, ${ }^{3}$ maharf@gmail.com, \\ ${ }^{4}$ supriyanto4id@gmail.com
}

Diajukan: 5 November 2019; Direvisi: 13 Mei 2020; Diterima: 3 Juni 2020

\begin{abstract}
Abstrak
Perangkat IoT yang diimplementasi pada banyak tempat dapat mengalami perubahan berupa update firmware. Update firmware pada perangkat IoT biasanya dilakukan dengan mengambil perangkat IoT, lalu menghubungkan ke komputer menggunakan komunikasi serial melalui kabel USB to micro USB, selanjutnya melakukan update firmware pada perangkat IoT dan mengembalikan perangkat IoT ke tempat. Jika sistem pada perangkat IoT sudah dapat berkomunikasi melalui antar muka jaringan, tidak perlu lagi menggunakan kabel USB to micro USB, karena bisa dimanfaatkan over the air update firmware menggunakan antar muka jaringan pada perangkat IoT. Over the air update firmware adalah memuat firmware hasil build dari Arduino IDE pada perangkat IoT menggunakan antar muka jaringan Wi-Fi, pada penelitian ini perangkat IoT menggunakan mikrokontroler ESP8266-12E. Untuk melakukan update firmware perangkat IoT digunakan protokol MQTT untuk menjembatani antara aplikasi berbasis website sebagai interface pengguna untuk publish file firmware ke perangkat IoT. Hasil dari implementasi aplikasi berbasis website untuk over the air update firmware pada perangkat IoT dengan protokol MQTT, dalam 10 kali pengujian pengiriman file firmware perangkat IoT menggunakan masing-masing QoS 0, QoS 1, dan QoS 2, didapatkan hasil QoS 2 lebih direkomendasikan untuk digunakan mengirim file firmware dengan keberhasilan update firmware $\operatorname{QoS} 0=50 \%$, QoS $1=70 \%$ dan $\operatorname{QoS} 2=80 \%$ dari 10 kali percobaan pengiriman file firmware pada perangkat IoT.
\end{abstract}

Kata kunci: Firmware Update, QoS, IoT, MQTT.

\begin{abstract}
IoT devices that are implemented in many places can experience changes in the form of firmware updates. Firmware update on an IoT device is usually done by taking an IoT device, then connecting to the computer using serial communication via a USB to micro USB cable, then updating the firmware on the IoT device and returning the IoT device to its place. If the system on the IoT device is able to communicate via a network interface, there is no need to use a USB to Micro USB cable, because it can be utilized over the air firmware update using the network interface on the IoT device. Over the air firmware update is loading firmware builds from Arduino Idea on an IoT device using a Wi-Fi network interface, in this study the IoT device uses an ES8266-12E microcontroller. Firmware update of the IoT device the MQTT protocol is used to bridge the website-based application as a user interfaces for PUBLISH firmware files to the IoT device. The results of the implementation of a website-based application for over the air firmware update on IoT devices with the MQTT protocol, in 10 times testing the sending of IoT device firmware files using each of QoS 0, QoS 1, and QoS 2, the results obtained QoS 2 are more recommended for use sending firmware files with successful firmware update $\operatorname{QoS} 0=50 \%, \operatorname{QoS} 1=70 \%$ and $Q$ oS $2=80 \%$ of 10 attempts to test the firmware file on an IoT device.
\end{abstract}

Keywords: Firmware Update, QoS, IoT, MQTT.

\section{Pendahuluan}

Pada akhir 2013, ada 9,1 miliar unit perangkat Internet of Things (IoT) dengan konektivitas Internet Protocol dan berkomunikasi tanpa interaksi dengan manusia. Internasional Data Corporation (IDC) memperkirakan pertumbuhan IoT yang diterapkan tiap tahun mencapai $17.5 \%$ diperkirakan menjadi 28,1 miliar di tahun 2020 [1]. Bahkan Cisco mempunyai prediksi dua kali lipat lebih besar yaitu 50 miliar pada tahun 2020 [2]. Perangkat IoT yang digunakan di berbagai tempat sering dianggap sebagai sistem 
yang tidak perlu mengubah requirements dan fungsinya. Namun, pada kenyataannya di mana perangkat IoT ini berjalan pasti akan berubah [3]. Perubahan ini meliputi perubahan behavior, parameter yang terkait komunikasi dengan sistem lain atau pengguna, memperbaiki kesalahan, bisa masalah keamanan, yang dilaporkan pengguna setelah perangkat IoT digunakan [3].

Berbagai perubahan perangkat IoT dapat dilakukan dengan mengganti firmware, untuk mengganti firmware pada perangkat IoT harus keluar mengambil perangkat IoT, menghubungkan ke komputer, melakukan update, dan mengembalikan perangkat IoT ke tempat. Namun, hal ini tidak dapat terus dilakukan bagi perusahaan yang memiliki perangkat IoT di berbagai tempat, seperti yang dilakukan Chrysler "merek mobil" pada tahun 2015 mereka dikritik karena mengirim perangkat flashdisk ke pelanggan untuk melakukan update firmware. Karena sangat rentan, flashdisk dapat diambil, dimodifikasi, dan dikirim kembali [4].

Jika sistem pada perangkat IoT sudah dapat berkomunikasi melalui antarmuka jaringan, hal ini bisa dimanfaatkan untuk menerapkan pembaruan firmware pada sistem IoT yang disebut dengan Over The Air (OTA) [3]. OTA dilakukan oleh Tesla pada tahun 2016 dengan mengirimkan pembaruan firmware pada mobil mereka dan konsumen dapat mengatur akan melakukan pembaruan pada saat mobil diparkir [4].

Over the air update adalah proses memuat firmware pada modul ESP "perangkat IoT" menggunakan koneksi jaringan Wi-Fi daripada menggunakan kabel port serial [5]. Secara umum istilah OTA adalah mekanisme penggunaan wireless untuk mengirim data, memperbarui paket untuk pembaruan firmware atau perangkat lunak ke perangkat mobile, sehingga pengguna tidak perlu pergi mengakses fisik perangkat untuk mengubah aplikasi, parameter, firmware, atau memperbarui software [6].

Over the air update pada perangkat IoT sudah ada di pasaran dalam produk merek Libelium, namun OTA hanya bisa dilakukan pada perangkat IoT Libelium melalui File Tranfer Protocol (FTP). Selain itu ada particle.io sama seperti Libelium hanya bisa digunakan untuk perangkat IoT yang mereka sediakan tidak bisa untuk perangkat lain. Selain dua perangkat berbayar Libelium dan particle.io, OTA di sediakan oleh Espressif melalui produk bernama ESP8266-12E, dapat melakukan update firmware melalui Arduino IDE, web browser, dan HTTP Server [5].

Over the air update dengan ESP8266-12E yang telah tersedia melalui Arduino IDE dan web browser memilik keterbatasan hanya bisa dilakukan dalam satu jaringan yang sama, dan HTTP Server bisa dilakukan dengan jaringan berbeda [5]. Namun pada penelitian pengujian sensing data suhu dan kelembapan pada penelitian sebelumnya menunjukkan protokol HTTP 6 kali lebih lambat melakukan transfer data daripada protokol MQTT dalam 60 detik. Dari 5 kali percobaan didapatkan rata-rata HTTP 934.4 data terkirim dan MQTT 6520.2 data terkirim [7].

Protokol MQTT adalah protokol pesan publish/subcribe, sangat sederhana, dan ringan, dirancang untuk perangkat yang terbatas oleh jaringan dengan bandwidth rendah, latensi tinggi, atau tidak dapat diandalkan. Prinsip desain protokol MQTT adalah untuk meminimalkan bandwidth jaringan dan kebutuhan sumber daya perangkat, sambil berusaha memastikan keandalan dan beberapa tingkat kepastian pengiriman data benar-benar terkirim Quality of Service (QoS) [8]. Contoh penggunaan protokol MQTT adalah Facebook Messenger [9] pada awal peluncurannya tahun 2011.

Berdasarkan latar belakang tersebut akan diimplementasikan protokol MQTT yang dapat melakukan over the air update pada perangkat IoT. Over the air update dengan protokol MQTT akan digunakan untuk melakukan update firmware dan software pada perangkat IoT, dari jaringan lokal atau jaringan internet, melalui media aplikasi berbasis website. Aplikasi berbasis website sebagai media interface pengguna untuk melakukan update file firmware dan melakukan monitoring hasil upload apakah berhasil atau tidak. Protokol MQTT digunakan sebagai media pengiriman file firmware hasil build dari Arduino IDE berupa file tipe bin, yang di-publish ke perangkat IoT yang telah melakukan subscribe pada suatu topic.

\section{Metode Penelitian}

Penerapan over the air update firmware dengan protokol MQTT dengan aplikasi berbasis website sebagai interface pengguna, dilakukan dengan beberapa tahapan, yaitu analisis sistem, desain arsitektur sistem, perancangan perangkat keras, perancangan perangkat lunak, implementasi sistem, dan pengujian sistem. 


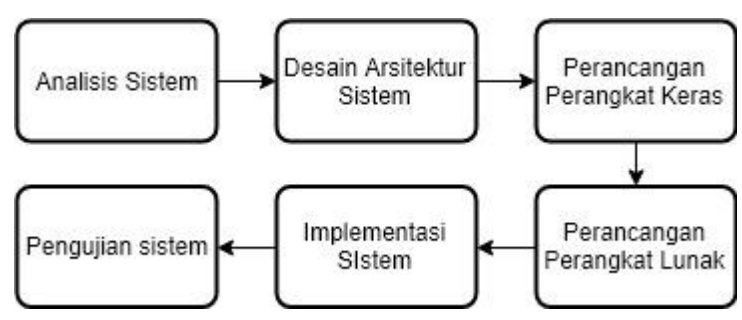

Gambar 1. Alur penelitian.

\subsection{Analisis Sistem}

Dari analisis masalah, maka dibuat server yang telah dikonfigurasi, untuk menjadi web server, menyimpan aplikasi berbasis web sebagai interface pengguna dan protokol MQTT berfungsi untuk jembatan komunikasi antara node perangkat IoT. Protokol MQTT adalah protokol komunikasi subscribe dan publish, di mana sebelum mengirim dan menerima pesan client harus terlebih dahulu terkoneksi dengan koneksi TCP ke server broker MQTT yang telah dikonfigurasi, selanjutnya publisher dan subscriber harus memiliki topik yang sama untuk saling komunikasi.

Publisher akan mengirim data ke server broker MQTT lalu broker akan mengirim ke subscriber. Identifikasi antara publisher dan subscriber harus memiliki topik yang sama agar pesan tersampaikan. Contohnya topik "rumah/dapur/suhu", jadi setiap publisher dan subscriber akan memiliki topik yang sama.

Over the air update firmware kepada perangkat IoT dilakukan dengan cara mengambil file firmware hasil compile dari Arduino IDE dengan ekstensi .bin, selanjutnya melakukan upload ke aplikasi berbasis web dan publish ke broker MQTT, lalu perangkat IoT melakukan subscribe dan menerima file ekstensi .bin selanjutnya melakukan update.

Aplikasi berbasis web dibuat dengan PHP Framework Codeigniter, pengguna harus login terlebih dulu, setelah login akan tampil pilihan untuk upload file firmware ekstensi .bin, form publish topik tujuan, dan button publish.

\subsection{Desain Arsitektur Sistem}

Arsitektur sistem penerapan protokol MQTT untuk over the air update firmware, menggunakan aplikasi berbasis website sebagai interface pengguna dengan rancangan topologi sebagai berikut.

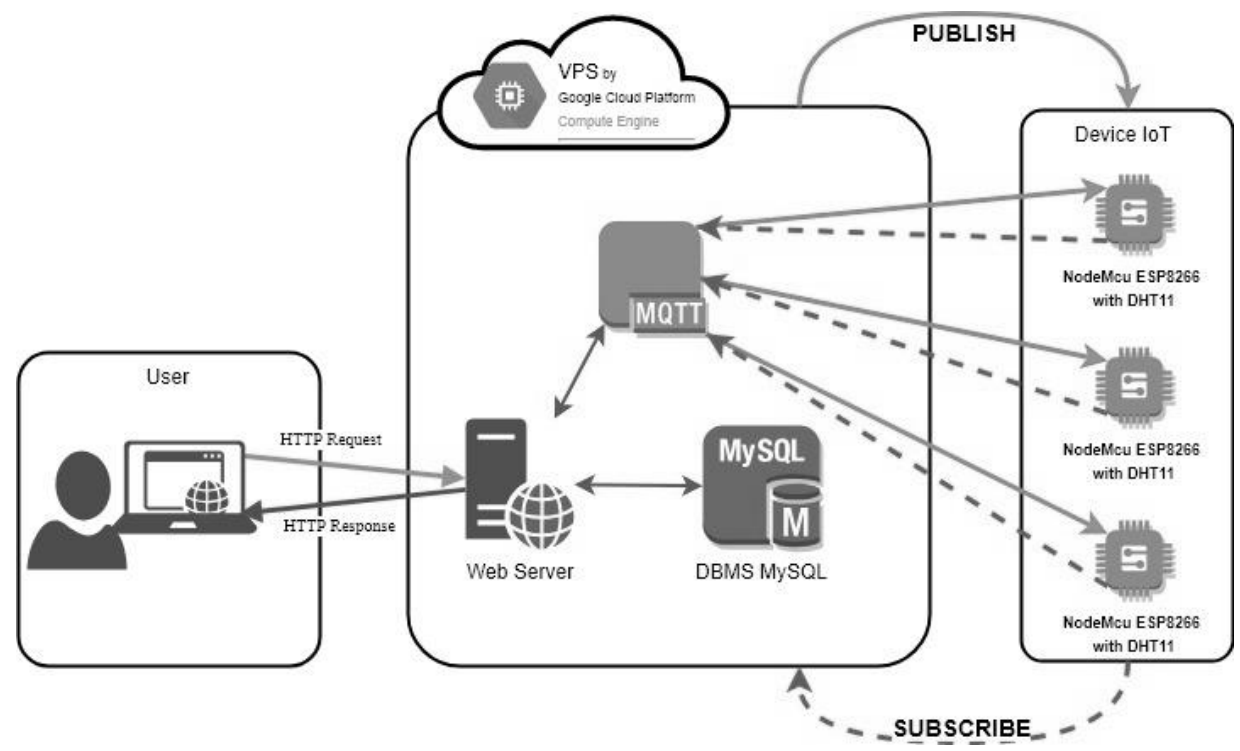

Gambar 2. Arsitektur system protokol MQTT untuk OTA update firmware perangkat IoT.

Dari rancangan topologi Gambar 2, terdiri dari Vitual Private Server (VPS) yang dikonfigurasi dengan protokol MQTT, web server Apache2, dan DBMS MySQL. Dalam penelitian ini, perangkat IoT yang digunakan adalah modul NodeMCU ESP8266-12E sebagai sensor node. Untuk sensing data suhu dan 
kelembapan menggunakan DHT 11. Sensor node tersebut akan menerima pembaruan firmware dan pengguna yang akan mengakses aplikasi berbasis web melalui browser.

Agar perangkat IoT dapat terhubung ke VPS, maka harus dihubungkan dengan Wi-Fi yang sudah terhubung ke internet. Begitu juga dengan aplikasi berbasis website yang akan diakses oleh pengguna melalui browser, harus dipastikan memiliki nama domain atau IP publik yang bisa diakses melalui browser.

Agar rancangan arsitektur sistem Gambar 2 dapat dilaksanakan sesuai dengan rancangan yang telah dibuat, maka dibutuhkan hardware dan software sebagai berikut;

Tabel 1. Software dan hardware sistem OTA dengan MQTT.

\begin{tabular}{ll}
\hline Software & Hardware \\
\hline Pengguna & Laptop \\
Windows 10 & Kabel USB 2.0 to Micro USB \\
Browser & \\
PuTTy & \\
Atom IDE & \\
\hline Server VPS & \\
\hline LAMP (Linux, Apache, MySQL, PHP) & CPU 1 GHz \\
Linux Ubuntu Server 16.04 & RAM 1 GB \\
Broker EMQTT 2.0 & Harddisk 10 GB \\
\hline Perangkat IoT & \\
\hline Arduino IDE & NodeMCU ESP8266-12E
\end{tabular}

Dari Tabel 1, hardware dan software terbagi menjadi 3 jenis yaitu untuk pengguna, Virtual Private Server, dan perangkat IoT.

\subsection{Rancangan Perangkat Keras}

Dari rancangan arsitektur, sistem over the air update firmware dengan protokol MQTT menggunakan aplikasi berbasis website sebagai interface pengguna. Rancangan hardware terdiri dari perangkat IoT, akses poin, komputer server, dan komputer pengguna seperti yang terlihat pada Gambar 3 di bawah ini.

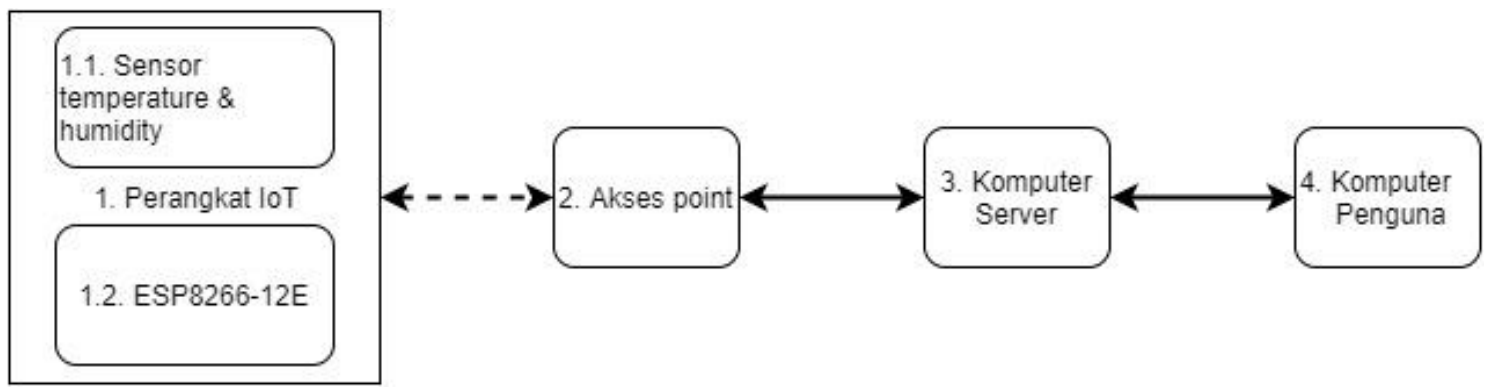

Gambar 3. Rancangan hardware protokol MQTT untuk OTA update firmware perangkat IoT.

Keterangan:

$\longrightarrow \rightarrow$ :Terhubung dengan jaringan $\mathrm{Wi}-\mathrm{Fi}$

$\longleftrightarrow$ :Terhubung ke jaringan internet

1. Perangkat IoT terdiri dari mikrokontroler dan sensor. Sensor temperature dan humidity menggunakan DHT 11 dan mikrokontroler menggunakan NodeMCU ESP8266-12E.

2. Akses poin yang sudah terhubung ke internet.

3. Komputer Server sebagai tempat meng-install web server Linux, Apache, MYSQL, PHP, dan menginstall EMQTT Broker.

4. Komputer pengguna untuk pengguna melakukan akses ke aplikasi berbasis website melalui browser untuk melakukan OTA dengan MQTT.

Perangkat IoT terdiri dari NodeMCU ESP8266-12E dan sensor DHT 11. NodeMCU ESP8266$12 \mathrm{E}$ digunakan untuk menerima update firmware dari aplikasi berbasis website yang dikirim oleh pengguna melalui protokol MQTT dan Sensor DHT 11 digunakan untuk monitoring apakah program pada firmware yang dikirim berfungsi atau tidak. Selain itu juga sensor digunakan untuk mengirim data temperatur dan humidity di sekitar perangkat IoT yang dikirim ke aplikasi berbasis website. Jadi akan dibuat dua firmware 
yang telah terisi program publish data sensor, dan subscribe topik firmware yang akan digunakan untuk menerima update dari aplikasi berbasis website, dengan rancangan skematis sebagai berikut.

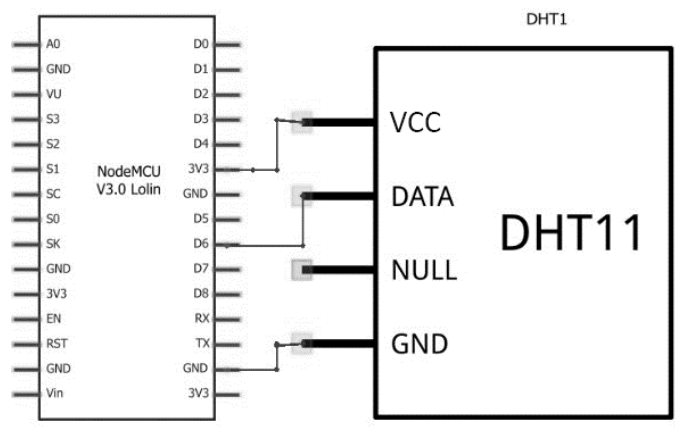

Gambar 4. Rangkaian skematis perangkat IoT.

Dari rangkaian skematis Gambar 4 DHT 11 memiliki 4 pin yaitu VCC, DATA, NULL, dan GND. Pin ini dihubungkan ke NodeMCU ESP8266-12E yaitu VCC dihubungkan ke 3V3, GND dihubungkan ke GND, dan DATA di hubungkan ke D6 pada NodeMCU ESP8266-12E.

\subsection{Rancangan Perangkat Lunak}

Perancangan perangkat lunak untuk setiap komponen pada sistem over the air update firmware dengan protokol MQTT, menggunakan aplikasi berbasis website yang akan diaplikasikan pada perangkat IoT dan server. Berikut adalah rancangan proses perangkat lunak pada Gambar 5.

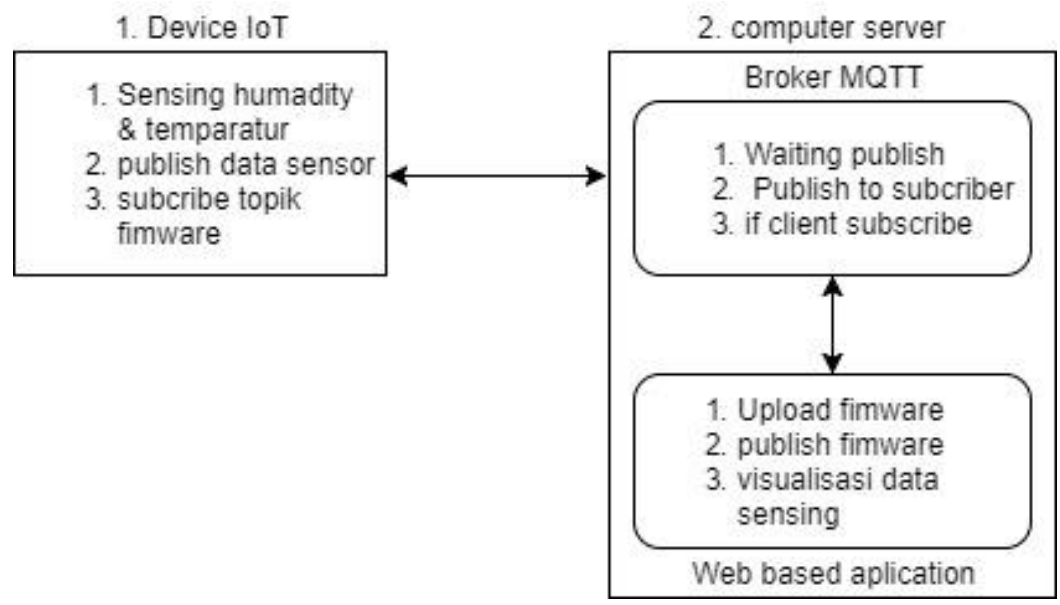

Gambar 5. Perancangan proses perangkat lunak.

Keterangan:

1. Desain proses perangkat lunak pada perangkat IoT.

2. Desain proses perangkat lunak pada komputer server.

$\longleftrightarrow$ Jaringan internet.

Dari desain perancangan proses perangkat lunak pada Gambar 5, perangkat lunak dibagi menjadi 2 bagian perangkat lunak pada perangkat IoT dan pada server. Perangkat lunak pada perangkat IoT melakukan sensing data sensor suhu dan kelembapan lalu melakukan publish data sensor dan melakukan subscribe topik firmware untuk menerima data firmware dari publish yang dilakukan aplikasi berbasis website. Pada server broker MQTT menunggu publish dari pengguna, jika ada yang melakukan publish dari pengguna maka broker akan melakukan publish kepada pengguna yang melakukan subscribe dan memiliki topik yang sama, pada aplikasi berbasis website melakukan subscribe data sensor dari perangkat IoT dan melakukan upload firmware lalu melakukan publish file .bin ke broker MQTT, lalu meneruskan ke perangkat IoT yang memiliki topik sama. 


\section{Hasil dan Pembahasan}

Setelah rancangan hardware dan software, selanjutnya adalah dilakukan pengujian untuk melihat kemampuan broker MQTT untuk mengirim file firmware melalui aplikasi berbasis website ke perangkat IoT dengan tahapan pengujian sebagai berikut.

a. Uji coba pengiriman file firmware konstan $276 \mathrm{~KB}$ untuk mendapatkan tingkat kegagalan dan keberhasilan update firmware pada perangkat IoT

b. Uji coba apakah kegagalan dan keberhasilan update firmware pada perangkat IoT berpengaruh terhadap delay

Dari hasil pengujian pengiriman file firmware konstan $276 \mathrm{~KB}$ untuk melakukan over the air update firmware pada perangkat IoT menggunakan aplikasi berbasis website, dibuat analisis untuk digunakan sebagai rekomendasi QoS yang digunakan saat mengirim file firmware dengan dua sub bab analisis antara lain: Pengaruh Penggunaan QoS Terhadap Keberhasilan dan Kegagalan Update Firmware pada Perangkat IoT dan Pengaruh Keberhasilan dan Kegagalan Update Firmware pada Perangkat IoT, terhadap Delay.

\subsection{Pengaruh Penggunaan QoS Terhadap Keberhasilan dan Kegagalan Update Firmware pada Perangkat IoT}

Dari 10 kali pengiriman file firmware ke perangkat IoT dengan menggunakan setiap QoS 0, QoS 1, dan QoS 2 didapatkan hasil perangkat IoT berhasil di-update dan restart sukses dan gagal sebagai berikut.

Tabel 2. Perangkat IoT sukses update firmware dan restart.

\begin{tabular}{cc}
\hline QoS & Updated Successfully \\
\hline QoS 0 & $50 \%$ \\
QoS 1 & $70 \%$ \\
QoS 2 & $80 \%$ \\
\hline
\end{tabular}

Dari Tabel 2 firmware yang berhasil di-update ke perangkat IoT, pada saat pengiriman dengan 10 kali percobaan pada QoS $0=50 \%$, QOS $1=70 \%$, dan QoS $2=80 \%$. Hasil update firmware ke perangkat IoT tersebut terjadi karena Quality of Service setiap QoS 0, QoS 1, dan QoS 2 memiliki paket kontrol MQTT yang berbeda-beda, sehingga jika menggunakan QoS 0 tingkat keberhasilan update firmware 50\% hanya melakukan publish firmware tanpa menerima kembali acknowledge puback. Jika menggunakan QoS 1 dengan tingkat keberhasilan update firmware $70 \%$, publish firmware akan mendapatkan balasan kembali berupa puback. Jika menggunakan QoS 2 dengan tingkat keberhasilan update firmare 80\%, paket kontrol MQTT yang digunakan pada saat proses publish firmware memiliki acknowledge sebanyak tiga paket kontrol MQTT yaitu pubrec, pubrel, dan pubcom, yang memastikan firmware benar-benar terkirim.

\subsection{Pengaruh Keberhasilan dan Kegagalan Update Firmware pada Perangkat IoT terhadap Delay}

Pengujian performa mengirim file firmware konstan, hanya menghitung delay yang terjadi dalam sistem ketika mengirim file firmware antara aplikasi berbasis website saat publish dan saat perangkat IoT menerima kontrol paket MQTT berisi file firmware, namun tidak menghitung delay yang terjadi pada saat perangkat IoT menerima file firmware lalu melakukan update kemudian melakukan restart perangkat IoT. Dalam proses perangkat IoT melakukan update lalu restart, inilah terjadi perbedaan waktu delay. karena ketika proses update firmware ini terjadi update firmware gagal dan update firmware berhasil. Jika update firmware berhasil proses akan lebih cepat dari pada ketika proses update firmware gagal, dengan hasil pengujian delay sebagai berikut.

Tabel 3. Delay pengiriman firmware, update firmware, dan restart perangkat IoT

\begin{tabular}{lc}
\hline QoS & Delay(s) Sending Firmware with Process Update \& Restart \\
\hline QoS 0 & 29.684037 \\
\hline QoS 1 & 39.807739 \\
\hline QoS 2 & 37.997534 \\
\hline
\end{tabular}

Tabel 3 adalah delay pada saat publish yang dilakukan aplikasi berbasis website dan diterima oleh perangkat IoT, ditambah dengan proses update firmware dan restart yang dilakukan perangkat IoT. Delay ketika menggunakan QoS 0 dengan proses update firmware dan restart didapatkan delay 29.684037/s, jauh berbeda dengan nilai delay QoS 0 delay pengiriman firmware, dengan nilai delay $0.105521 / \mathrm{s}$, perbedaan 
ini terjadi karena nilai delay QoS 0 ditambah dengan proses update firmware dan restart perangkat IoT lalu mengirimkan paket publish berisi version update firmware.

Pada delay QoS 1 dan QoS 2 memiliki nilai delay yang meningkat dari pada delay pengiriman firmware. Hal ini terjadi karena ada proses update firmware dan restart perangkat IoT pada saat menerima file firmware, proses update firmware dan restart perangkat IoT dapat terjadi berhasil dan gagal update firmware ke perangkat IoT, jika proses update firmware berhasil maka delay akan menjadi lebih cepat, daripada jika gagal akan menjadi lebih lama. Dari delay proses pengiriman file firmware dikurang dengan delay proses update firmware dan restart perangkat IoT didapatkan hasil delay tertinggi pada masingmasing QoS 0, QoS 1, dan QoS 2 sebagai berikut.

Tabel 4. Hasil delay pengiriman firmware dikurangi delay proses update dan restart.

\begin{tabular}{cc}
\hline QoS & Delay Sending Firmware - Delay with Process Update and Restart \\
\hline QoS 0 & 29.578506 \\
\hline QoS 1 & 19.702856 \\
\hline QoS 2 & 17.863652 \\
\hline
\end{tabular}

Tabel 4 adalah hasil pengurangan delay pada Tabel 3, untuk melihat delay tertinggi pada saat aplikasi berbasis website publish firmware lalu diterima oleh perangkat IoT, dan melakukan update firmware kemudian melakukan restart perangkat IoT. Pada QoS 0 memiliki nilai delay tertinggi 29.578506/s karena mengikuti tingkat kegagalan pada saat proses update firmware yang hanya terkirim 50\%, berikutnya QoS 1 delay tertinggi kedua 19.702856/s dengan tingkat kegagalan proses update 30\% dan pada QoS 2 memiliki tingkat delay 17.663625/s dengan tingkat kegagalan proses update 20\%. Dari proses update firmware yang berhasil dan gagal pada saat proses update firmware dilanjutkan restart perangkat IoT dapat disimpulkan bahwa pada saat update firmware perangkat IoT, penggunaan QoS 2 lebih disarankan dari pada QoS 1 dan QoS 0, karena tingkat kegagalan pengiriman update firmware menggunakan QoS $2=20 \%$ atau 2 kali kegagalan dari 10 kali percobaan pengiriman, namun penggunaan QoS 2, juga berpengaruh ke pada penggunaan sumber daya CPU dan memory paling tinggi dari pada QoS 0 , dan QoS 1.

\section{Kesimpulan}

Dari hasil pengujian pengiriman file firmware untuk over the air update firmware perangkat IoT didapatkan hasil direkomendasi menggunakan QoS 2 karena tingkat keberhasilan pengiriman file firmware dalam 10 kali percobaan adalah $80 \%$ dari pada QoS $1=70 \%$ dan QoS $0=50 \%$. Penggunaan QoS 2 pada saat mengirim file firmware mengakibatkan penggunaan sumber daya CPU dan memory juga tinggi dari pada menggunakan QoS 1 dan QoS 0. Tingkat kegagalan QoS $0=50 \%$, QoS $1=70 \%$, dan QoS $2=80 \%$ berpengaruh terhadap delay pada saat mengirim file firmware. Dengan delay tertinggi QoS $0=29.578506 / \mathrm{s}$, diikuti QoS 1 = 19.702856/s , dan delay terendah QoS $2=17.663625 / \mathrm{s}$.

\section{Daftar Pustaka}

[1] D. Lund and M. Morales, "Worldwide and Regional Internet of Things ( IoT ) 2014 - 2020 Forecast : A Virtuous Circle of Proven Value and Demand," IDC Anal. Futur., no. May, p. 29, 2014.

[2] D. Evans, "The Internet of Things How the Next Evolution of the Internet Is Changing Everything," 2011.

[3] S. Reißmann and C. Pape, "An Over the Air Update Mechanism for ESP8266 Microcontrollers," ICSNC 2017 Twelfth Int. Conf. Syst. Networks Commun. An, no. October, pp. 11-17, 2017.

[4] Lee Jeffrey, "Over-The-Air Firmware: The Critical Driver of IoT Success - DZone IoT," https://dzone.com, 2017.

[5] ESP8266, "OTA Update · ESP8266 Arduino Core."

[6] A. S. A. Quadri and B. . O. Sidek, "An Introduction to Over-the-Air Programming in Wireless Sensor Networks," Int. J. Comput. Sci. Netw. Solut., vol. 2, pp. 33-49, 2014.

[7] M. K. H. R A Atmoko*, R Riantini, "IoT real time data acquisition using MQTT protocol," Int. Conf. Phys. Instrum. Adv. Mater., vol. 012003, 2016.

[8] N. A. Stanford Clark Andy, "MQTT," IBM, 1999.

[9] Zhang Lucy, "Building Facebook Messenger," 2011. 